\title{
An Instrument for Measuring Perception Levels on TQM Practices among R\&D Center Employees in Saudi Arabia
}

\author{
Khalid I. Alshitri \\ King Abdulaziz City for Science and Technology (KACST), Riyadh, Saudi Arabia \\ Correspondence should be addressed to: Khalid I. Alshitri; kalshitri@kacst.edu.sa
}

Received date: 28 November 2013; Accepted date: 28 November 2013; Published date: 17 November 2014

Academic Editor: Elspeth McKay

Copyright (C) 2014. Khalid I. Alshitri. Distributed under Creative Commons CC-BY 3.0

\begin{abstract}
The purpose of the study is to develop and validate an instrument to measure perception on TQM practices among research and development (R\&D) center employees. Empirical data were collected from 102 employees in a public R\&D center in Saudi Arabia. The content validity, construct validity, criterion-related validity, and reliability were examined. Results showed that the instrument is a reliable and valid tool in measuring the employees' perception on TQM practices. This produces a relatively compact instrument comprising four TQM variables with 22 items that allows researchers and practitioners to measure perceived TQM implementation among all types of employees and TQM program levels in public organizations. Suggestions for using the instrument are presented.
\end{abstract}

Keywords: Total quality management, employees' perception, R\&D, Saudi Arabia.

\section{Introduction}

Total quality management (TQM) is a holistic management philosophy focusing on the maintenance and continuous improvement of products, services, people, and processes at all levels and in all functions of the organization with the goal to meet or exceed customer expectations (Flynn et al. 1994; Goetsch and Davis 1994; Oakland 2003). TQM becomes critical for organization's competitiveness, effectiveness, and survival. However, the implementation of TQM is one of the most complex activities that any organization can attempt, the main reason being that it involves a change in working culture and influence the work practices of individual employees (Guimaraes 1996). These changes may have an effect on employees' daily work and their job satisfaction and intentions to stay (Lam 1995), and without satisfied and motivated employees it is impossible to produce quality products and services and it is impossible to achieve satisfied and loyal customers (Eskildsen and Dahlgaard 2000). 
Research and development (R\&D) defined as "an activity that is aimed at generating new knowledge, testing hypotheses about how matters in the physical or social world act and react, and in general, providing know-how which can be used to create or improve activities or systems in that part of our life to which they pertain" (Salasin and Hattery 1977). R\&D centers were established to perform, analyze, integrate, support, and manage basic or applied research and development. It becomes of great importance in business as the level of competition, production, processes, and methods are rapidly increasing. The importance of $R \& D$ centers for meeting business need is made clear by the phenomenal growth in the budgets that allocated for R\&D activities. For example, it has been found that the $R \& D$ expenditure (as a percentage of GDP) in the private and public sectors increased marginally in the EU-27, Japan, and USA during the period 2000-2008 from $1.83 \%$ to $1.92 \% ; 3.04 \%$ to $3.45 \%$; and $2.69 \%$ to 2.79 $\%$, respectively (European-Union 2012). Unfortunately, R\&D is very difficult to manage due to the rapid pace of change of the R\&D knowledge base and the considerable uncertainty associated with the outcome of R\&D activities (Clarke 2002).

Increased attention has been paid to employees' attitudes in the management literature. Employees' attitudes such as job satisfaction and organizational commitment is associated with many important behaviors and outcomes for employees that have implication for organizational and personal well-being (Spector 1985; Meyer et al. 2002). Several studies indicate that satisfied and committed employees represent value to an organization and that they are the most important drivers of continuous improvement in most TQM literature (e.g. (Deming 1986; Flynn et al. 1994)). Without satisfied and motivated employees, it is impossible to produce quality products and services and impossible to achieve satisfied and loyal customers (Eskildsen and Dahlgaard 2000). This explains why people dimension is included as a criterion in most of the
Excellence Models. With the high employees' demand, the extremely short supply, rising personnel costs, and high rates of turnover (Baroudi 1985; Igbaria and Guimaraes 1993; Kochanski and Ledford 2001; Lazar 2001; Chang et al. 2008; Alshitri 2013), human resource departments in many organizations are experiencing greater pressure from top management to improve the recruitment, motivation, and retention of highly skilled professionals.

TQM's impact on employees' job satisfaction, organizational commitment, and intentions to stay has been addressed by several studies (e.g. (Guimaraes 1996; Eskildsen and Dahlgaard 2000; Boon et al. 2006; Ooi et al. 2007; Tutuncu and Kucukusta 2007)). One would hope that many of the findings will be applicable to R\&D centers' personnel. However, there is considerable evidence that R\&D centers' personnel differ from other employees on a number of values, attitudes, and motivational factors. It has been noted that R\&D professionals have a value system which emphasizes independence, freedom, and autonomy to make decisions concerning their work (Clarke 2002). In addition, it has been reported that, $R \& D$ professionals have low levels of attachment to their employing organization (Chang et al. 2008). There is also evidence that R\&D professionals generally respond more positively to intrinsic forms of reward and recognition such as praise and feedback from their peers (Clarke 2002). These findings have major implications for the management of R\&D centers and further highlight the need to examine the impact of TQM on employees' job satisfaction and intentions to stay. However, despite the great importance of the topic, a survey of the literature indicates that TQM research, for the most part, deals with the manufacturing and service sectors and lacks R\&D focus.

The primary objective of this study is to develop a reliable and valid instrument to measure perception levels on TQM practices (leadership, strategic planning, people management, and process management) among R\&D center employees in Saudi Arabia. 
To the author's knowledge, the present study is the first study that had attempted to identify the key attributes for successful TQM implementation and their effect on job satisfaction, organizational commitment, and intentions to stay among R\&D centers employees Saudi Arabia.

\section{Theoretical Background}

There is a general agreement that a systematic method or framework is needed to put TQM into practice. However, there is no universally accepted TQM frameworks (Yusof and Aspinwall 2000), and different approaches coexist in the literature to implement TQM including consultants-based frameworks such as (Ishikawa 1985; Deming 1986), standardized-based frameworks such as the ISO 9000 series (ISO9000 2000), and other frameworks based on empirical studies such as (Saraph et al. 1989; Flynn et al. 1994; Powell 1995; Ahire et al. 1996). In addition, several authors (e.g. (Samson and Terziovski 1999; Eskildsen and Dahlgaard 2000; BouLlusar et al. 2009)) have proposed that frameworks based on quality awards fit the definition of TQM, hence the introduction of the European Quality Award (EFQM Excellence Model), the most widely used model for self-assessment in Europe (Eskildsen and Dahlgaard 2000), and has become the basis for the majority of national and regional Quality Awards. Five TQM dimensions have been incorporated in the model: leadership, strategic planning, people management, partnership and resources, and process management.

Contrary to other TQM practices, the combination of leadership, strategic planning, people management, and process management dimensions were chosen for several reasons. First, several researchers such as (Eskildsen and Dahlgaard 2000; Tutuncu and Kucukusta 2006; Bou-Llusar et al. 2009) have used these dimensions to signify TQM practices when conducting their research studies. Second, as argued by Bou-Llusar et al. (Bou-Llusar et al. 2009), these dimensions consist of both soft and hard TQM factors, in which the soft TQM factors comprise leadership and people management and the hard TQM factors include processes management; while strategic planning contains items that relate to both soft and hard issues (Bou-Llusar et al. 2009). Finally, the Fundamental Concepts of these dimensions are applicable to all organizations regardless of sector, size, structure, or maturity when examining the effective management of their TQM practices. Due to these reasons, the current research study will adopt leadership, strategic planning, people management, and process management to measure employees' perception levels on TQM practices among $R \& D$ center employees in Saudi Arabia.

\section{Leadership}

Leadership refers to "the ability to inspire people to make a total, willing, and voluntary commitment to accomplishing or exceeding organizational goals" (Goetsch and Davis 1994). The aim of leadership should be to improve the performance of people and machines, to improve quality, to increase output, and simultaneously to bring pride of workmanship to employees (Deming 1986). TQM advocates, such as (Samson and Terziovski 1999), emphasize the activities of senior leadership much like transformational leadership theory. Transformational leadership theory suggests that leaders enhance the motivation, morale, and performance of employees by moving them beyond immediate self-interests through idealized influence (charisma), inspiration, intellectual stimulation, or individualized consideration (Bass 1990). Leadership was reported to be positively associated with employees' job satisfaction, organizational commitment, and intentions to stay (Ugboro and Obeng 2000; Meyer et al. 2002; Berson and Linton 2005; Voon et al. 2011). For example, Spector (Spector 1985) found that leadership is positively related to satisfaction regarding pay, promotion, supervision, rewards, coworkers, and nature of work as well as total satisfaction. 


\section{Strategic Planning}

An organization strategy is a long-term direction and objectives which affect the whole of the organization and of course this must have an impact on employees. Strategic planning defined as "a systematic process for managing the organization and its future direction in relation to its environment and the demand of external stakeholders, including strategy formulation, analysis o agency strengths and weaknesses, identification of agency stakeholders, implementation of strategic actions, and issue management" (Berry and Wechsler 1995). Participation in strategic planning process can affect job satisfaction, organizational commitment, and intentions to stay in two ways. First, it allows employees to influence their working environment in the broadest possible manner which can fulfill their self-actualization needs, and the more employees fulfill their needs the greater will be their satisfaction (Maslow 1943). Second, participation in strategic planning allows employees to engage in role clarification and conflict resolution activities which can reduce role ambiguity and role conflict during the implementation of strategic plans (Daniels and Bailey 1999; Teh et al. 2009), which lead to higher level of job satisfaction, more committed to their organizations, and finally, less likely to leave (Baroudi 1985; Iqbaria and Siegel 1992). A study by (Kim 2000), investigating the relationship between participation in strategic planning process and employees' job satisfaction, revealed that employees who perceive they have input in a department's strategic plan development express higher levels of job satisfaction than others who do not. The study also supports the view that employees' clear understanding of their roles in accomplishing the goals in strategic plan is positively associated with job satisfaction.

\section{People Management}

Employees at all levels are the essence of an organization and their full involvement enables their abilities to be used for the organization's benefit. Excellent organizations value their people and create a culture that allows the mutually beneficial achievement of organizational and personal goals; they develop the capabilities of their people and promote fairness and equality; and they care for, communicate, reward and recognize, in a way that motivates people, builds commitment and enables them to use their skills and knowledge for the benefit of the organization, as well as provide employees with relevant information, equipment, and tools; and providing them with a safe and healthy workplace (EFQM 2010). People management was reported to be positively associated with employees' job satisfaction, organizational commitment, and intentions to stay (Morrow 1997; Boon et al. 2006; Jun et al. 2006; Ooi et al. 2007). Jun et al. (Jun et al. 2006) found that HR-focused TQM practices (employee empowerment, teamwork, and employee compensation) are positively related to employees' overall job satisfaction and loyalty. Ooi et al. (Ooi et al. 2007), Morrow (Morrow 1997), and Boon et al. (Boon et al. 2006) further concluded that teamwork was perceived as a dominant TQM practice that affect job satisfaction and organizational commitment.

\section{Process Management}

Process management is a set of methodological and behavioral practices which are implemented to manage and improve processes that produce products and services (Anderson et al. 1994). A process is a set of activities, methods, and practices. It involves changing existing practices and organizational structures. It is however very important that there are humans involved in any process and any action made needs to take this fact into account. Likewise, desired results in organization would be ensured by standardization and formalization of activities, methods, and practices (IS09001 2008). Formalization refers to the "extent to which rules, procedures, instructions, and communication are written" (Pugh et al. 1968). The presence of written rules, standards, and policies, will significantly reduce role ambiguity and role conflict in a 
highly formalized organization (Wetzels et al. 2000; Teh et al. 2009), thus lead to more involved, motivated, satisfied, and committed employees, and eventually display a propensity to stay within the organization (Baroudi 1985; Iqbaria and Siegel 1992). Moreover, several studies such as (Eskildsen and Dahlgaard 2000; Kohlbacher 2010) have reported a positive relationship between process management and job satisfaction.

\section{Methodology}

\section{Sample and Procedures}

Sampling design and sample size are important subjects to statistically represent the population and to be able to suggest implications both for theory and practice. Simple random sampling design was used for the survey due to its efficiency. It means that each member of the population should have an equal chance of being chosen and selected as a subject. The sample population of this study was limited to employees within various departments working in a TQM organization. Any attempt to examine the relationships between TQM and organizational performance must focus on organization that has implemented TQM effectively. This is important because while most organizations will claim that they have implemented TQM, few are doing it effectively. Effective implementation means that the key principles of TQM are well accepted, practiced, and deployed within the organization. We used the ISO 9001:2008 certified organization as a proxy for effective implementation of TQM. The ISO9000 series certification implies that a TQM system is running in these organizations (Ho et al. 1999), although this system may not be observed at an organization wide scale. Therefore, data were collected from employees within various departments of a large IS09001:2008 certified public organization located in Riyadh, Saudi Arabia.

The data for this study were primarily collected through a structured questionnaire hosted on the web where respondents answered research questions online. Online questionnaires have their valuable advantages which include: the possibility of a large and geographically dispersed sample size and the low likelihood of contamination or distortion of respondent's answer. In addition, using this approach provides the opportunity to conduct surveys more efficiently and effectively than the traditional means. The primary reason for the utilization of the internet was due to time saving. The questionnaire was distributed online using gmail.com web tools, which send personalized email invitations to 137 employees. Respondents were given 14 days to complete the questionnaire. The completion of the electronic questionnaires was personally administered and anonymously handled. After all the responses had been collected, they were carefully reviewed and verified. A total of 102 responses were collected and analyzed, which represents a $74.5 \%$ response rate. The survey was conducted in January 2013. All instructions and questions were translated from English into Arabic in order to help all participants understand easily these surveys.

\section{Measures}

The questionnaire instrument consisted of three parts. The first part involved four questions regarding basic demographic characteristics of the respondents (gender, age, education level, and tenure). TQM practices comprised the second part of the instrument. It includes 22 questions and it assesses four practices (leadership, strategic planning, people management, and process management). The input to the development of this questionnaire has been EFQM material (EFQM 2010), the Malcolm Baldrige National Quality Award (MBNQA 2010), previous studies that construct questionnaires according to business excellence model such as (Eskildsen and Dahlgaard 2000; Tutuncu and Kucukusta 2006; Bou-Llusar et al. 2009) and focus group sessions in the organization. The purpose of this instrument was to measure the level of the employees' perception on TQM implementation and presented statements such as "Top management inspires people and create a 
culture of excellence that helps me do my job". For each item, respondents were asked to indicate the extents of their personal agreement using a 5-point Likert-type scale ranging from (1) strongly disagree to (5) strongly agree. The final part involves one question regarding the overall job satisfaction among R\&D center employees. It was assessed by a single item: overall, I am satisfied with my job. Respondents were asked to indicate the extents of their personal agreement using a 5point Likert-type scale ranging from (1) strongly disagree to (6) strongly agree. The item was scored such that high scores reflect stronger overall job satisfaction. The survey instrument was pilot tested among 5 employees. The pilot results were used to improve the clarity and readability of questions.

\section{Data Analysis}

The data obtained were analyzed by using SPSS for Windows 20.0 program. Descriptive and inferential statistics were used to analyze the data. Pearson-product moment correlations and stepwise multiple regression analysis were performed to test the research hypothesis. A cut-off point of $p<0.05$ was considered to indicate whether the relationship between the two factors is 'statistically significant'. A practical effect size of $r$ as $(<+/-0.1$ weak, $<+/-0.3$ modest, $<+/-$ 0.5 moderate, $<+/-0.8$ strong, and $>=+/-0.8$ very strong) was also considered for the correlation analysis to interpret the practical significance of the findings (Cohen et al. 2000). In terms of the multiple regression analysis, the value of $\mathrm{R}^{2}$ was used to determine the proportion of variance of the dependent variables (job satisfaction and intentions to stay) that is explained by the independent variable (TQM practices). The F-test was used to test whether there was a significant regression ( $\mathrm{p} \leq 0.05)$ between the independent and dependent variables. For the purposes of this study, $\mathrm{R}^{2}$ values larger than 0.15 (medium effect) (Cohen et al. 2000) were regarded as practically significant. The data obtained were analyzed using SPSS for Windows 20.0 program.

\section{Results}

Respondents Profile

There were 69 male and 33 female respondents. The age range of the sample was from 22 years to 51 with a mean of age 29.7 years. Out of 102 respondents, 81 (over 79 percent) had completed bachelor degree or above. Employees from three different majors were represented in the sample (information technology $=44$, engineering $=35$, science $=4$, others $=19$ ). The working experience range of the sample was from less than 2 years to 16 or more years with a mean of 4.1 years. Employees from three types of job levels groups were represented in the sample (senior management/executive $=4$, middle management $=22$, and non-management $=$ 76). The senior management/executive group included senior managers responsible for several work areas. The middle management group included middle managers and supervisors responsible for a single section or group. The non-management group included IT professionals, research scientists, most types of engineers, and product and project managers.

\section{Validity and Reliability of the TQM Subscales}

In order to explore the possible relationships between the research variables in this study, the measurement instruments should be reliable and valid and should be evaluated for this. In evaluating measurement instruments, content validity, construct validity, criterionrelated validity, and reliability analysis should be conducted in order to understand whether the measurement instruments were reliable and valid. It is worth to note that these methods are used as tools and the researcher accepting their validity.

First, it was argued that the four scales for measuring TQM factors had content validity since the development of these measurement items was based mainly on an extensive review of the literature and detailed evaluations by academicians and practitioners from both TQM and organizational behavior 
fields. They generally do measure the key fields of the TQM and job satisfaction elements.

Second, construct validity measures the extent to which the items in a scale all measure the same construct (Flynn et al. 1994). It can be evaluated by the use of factor analysis (Hair et al. 1992). The measurement items for each of the TQM factors were factor analyzed, see Table 1. The items assigned to each of the four TQM factors have been subjected to factor analysis to ensure that they are reliable indicators of those factors (Nunnally 1967). A cutoff loading of 0.35 has been used to eliminate items that are weak indicators of the factors. All the 22 items were above this cutoff. The internal consistency reliabilities (coefficients alpha) was computed for each
TQM factor, and each was above the 0.70 minimum suggested by (Nunnally 1967) for early stage research. The factor scores for the first four TQM constructs were used as independent variables in a multiple regression analysis.

Third, criterion-related validity is known as predictive validity or external validity, "It is concerned with the extent to which a measuring instrument is related to an independent measure of the relevant criterion" (Saraph et al. 1989). The criterion related validity of the model was determined by examining the Multiple R coefficient computed for the four TQM variables and overall job satisfaction $\left(R^{2}\right.$ $=0.317)$. This indicates that the TQM factors have a reasonably high degree of criterionrelated validity when taken together.

Table 1: Factor analysis and reliability for the TQM subscales

\begin{tabular}{|c|c|c|c|c|}
\hline Measures & Factor loading & Eigenvalue & $\begin{array}{c}\text { Variance } \\
\text { Explained (\%) }\end{array}$ & Reliability \\
\hline Leadership & 0.71-0.86 & 3.65 & 60.78 & .87 \\
\hline \multicolumn{5}{|c|}{ 1. I know my organization's mission (what it is trying to accomplish) } \\
\hline \multicolumn{5}{|c|}{ 2. I know my organization's vision (where it is trying to go in the future) } \\
\hline \multicolumn{5}{|c|}{ 3. Top management uses our organization's values to guide us } \\
\hline \multicolumn{5}{|c|}{$\begin{array}{l}\text { 4. Top management leads the improvement of the organization's management system and } \\
\text { performance }\end{array}$} \\
\hline \multicolumn{5}{|c|}{ 5. Top management inspires people and creates a culture of excellence that helps me do my job } \\
\hline \multicolumn{5}{|c|}{ 6. Top management shares information about the organization } \\
\hline Strategic planning & 0.76-0.87 & 2.06 & 68.81 & .77 \\
\hline \multicolumn{5}{|c|}{ 7. Top management asks what I think } \\
\hline \multicolumn{5}{|c|}{ 8. As it plans for the future, top management asks for my needs and expectations } \\
\hline \multicolumn{5}{|c|}{ 9. Top management encourages totally new ideas (innovation) } \\
\hline People management & $0.56-0.78$ & 4.30 & 47.82 & .85 \\
\hline \multicolumn{5}{|c|}{ 10. The people I work with cooperate and work as a team } \\
\hline \multicolumn{5}{|c|}{$\begin{array}{l}\text { 11. My bosses encourage me to develop my skills, knowledge, and capabilities so I can advance in my } \\
\text { career }\end{array}$} \\
\hline \multicolumn{5}{|c|}{ 12. I am rewarded and/or recognized for my work } \\
\hline \multicolumn{5}{|c|}{ 13. I am allowed to make decisions to solve my work problems } \\
\hline \multicolumn{5}{|c|}{ 14. My bosses and my organization care about me } \\
\hline \multicolumn{5}{|c|}{ 15. I get all the important information I need to do my work } \\
\hline 16. I have a safe and heal & & & & \\
\hline
\end{tabular}


17. I can get everything I need (e.g. tools) to do my job

\begin{tabular}{|c|c|c|c|c|}
\hline Process management & 0.61-0.87 & 2.97 & 59.36 & .83 \\
\hline \multicolumn{5}{|c|}{ 18. We have good processes for doing our work } \\
\hline \multicolumn{5}{|c|}{ 19. I know how to measure and improve the quality of my work } \\
\hline \multicolumn{5}{|c|}{ 20. I know who my most important customers are } \\
\hline \multicolumn{5}{|c|}{ 21. I regularly ask my customers what they need and want } \\
\hline
\end{tabular}

Finally, reliability is defined as the degree of consistency of a measure. Internal consistency is the most commonly used psychometric measure in assessing reliability of survey instruments and scales (Nunnally 1967). It is an indicator of how well the different items measure the same factor. Internal consistency can be measured using a reliability coefficient such as Cronbach Alpha. Using the SPSS for Windows reliability test program, an internal consistency analysis was performed separately for TQM subscales as shown in Table 1. All subscales reliabilities are above the 0.70 minimum suggested by (Nunnally 1967). Considering the above findings, it can be concluded that this instrument is reliable and valid. Therefore, the data obtained from them can be used for subsequent data analysis.
Relationships between Research Variables

Table 2 presents the means, standard deviations (S.D.), and correlations among the variables examined in this study. The correlation matrix reveals that TQM variables (leadership, strategic planning, people management, and process management) are highly correlated with each other. Similarly, all TQM variables are positively correlated with job satisfaction. People management $(r=.506$, $\mathrm{p} \leq .01)$ and leadership $(\mathrm{r}=.478, \mathrm{p} \leq .01)$ are highly correlated with job satisfaction. However, overall job satisfaction is also related to the other TQM variables but with smaller correlation coefficients.

Table 2: Correlations among study variables

\begin{tabular}{|c|c|c|c|c|c|c|c|}
\hline Measures & Means & S.D. & 1 & 2 & 3 & 5 & 6 \\
\hline 1. Leadership & 3.50 & .78 & 1 & & & & \\
\hline 2. Strategic planning & 3.22 & .91 & $.715^{* *}$ & 1 & & & \\
\hline 3. People management & 3.71 & .73 & $.616^{* *}$ & $.616^{* *}$ & 1 & & \\
\hline 4. Process management & 3.52 & .84 & $.639 * *$ & $.473^{* *}$ & $.437^{* *}$ & 1 & \\
\hline 5. Overall job satisfaction & 4.52 & .74 & $.478^{* *}$ & $.316^{* *}$ & $.506^{* *}$ & $.326^{* *}$ & 1 \\
\hline
\end{tabular}

**. Correlation is significant at the 0.01 level (2-tailed).

\section{Discussion and Implications}

The study has developed and validated an instrument that measures employees' perception towards the TQM implementation structured around the EFQM Excellence Model 2010 criteria. The instrument comprises four TQM variables with twenty-two items that could facilitate the TQM implementation in public R\&D centers in Saudi Arabia.
The results of this study indicate that the TQM framework, as modelled, is a valid and reliable instrument in measuring TQM practices and predicting job satisfaction, organizational commitment, and intentions to stay among R\&D center employees. They also show that TQM practices are highly correlated with each other. This indicates that there is clearly some significant multicollinearity which reflects, as would be expected, that organizations which 
are advanced in their practices on some variables tend generally to be more advanced on others. These findings support the argument that the TQM practices should be implemented holistically rather than on a piecemeal basis to get the full potential of them (Ahire et al. 1996).

The instrument provides compatible tool for management to see if their perceptions agree with those of organization's employees. Public R\&D centers could use the instrument to determine the extent to which the four TQM variables are implemented from employees' perspectives. This would help senior management focus the improvement and communication efforts on areas needing the most attention. This also would help senior management to understand what is important to their employees and keep them focused on employees' issues that need to be solved in order to get the most out of their employees as well as the allocation of resources to those practices that have the most significant effect on employees' outcomes.

Last, some words of caution and an invitation for further research. This study, nevertheless, has its limitations which suggest some directions for possible extensions in the future. First, the study is based solely on data from one public organization in Saudi Arabia. Additional research, using a wider and a larger sample of participants than those represented in the present convenience sample, is necessary in order to confirm the generalizability of the findings to a larger population of employees in public organizations and/or private organizations. Second, future research would validate the importance of individual variable on measuring employee perception towards TQM implementation. Finally, future studies could use this instrument to examine the TQM's impact on employees' outcomes, more specifically, whether it is associated with employees' job satisfaction, organizational commitment, and intentions to stay among employees in the public and/or private organizations.

\section{References}

1. Ahire, S. L., D. Y. Golhar, et al. (1996). "Development and Validation of TQM Implementation Constructs." Decision Sciences 27: 23-56.

2. Alshitri, K. I. (2013). "The Effects of the Personal Variables on Organizational Commitment in Public Organizations in Saudi Arabia." IBIMA Business Review 2013.

3. Anderson, J. C., M. Rungtusanatham, et al. (1994). "A Theory of Quality Management Underlying the Deming Management Method." The Academy of Management Review 19(3): 472-509.

4. Baroudi, J. J. (1985). "The impact of role variables on is personnel work attitudes and

intentions." MIS Quarterly 9(4): 341-356.

5. Bass, B. M. (1990). "From transactional to transformational leadership: Learning to share the vision." Organizational dynamics 18(3): 19-31.

6. Berry, F. S. and B. Wechsler (1995). "State Agencies' Experience with Strategic Planning:

Findings from a National Survey." Public Administration Review 55(2): 159-168.

7. Berson, Y. and J. D. Linton (2005). "An examination of the relationships between leadership style, quality, and employee satisfaction in R\&D versus administrative environments." R\&D Management 35(1): 51-60.

8. Boon, O. K., M. S. Safa, et al. (2006). "TQM Practices and Affective Commitment: A Case of

Malaysian Semiconductor Packaging Organizations." International Journal of Management and Entrepreneurship 2(1): 37-55. 
9. Bou-Llusar, J. C., A. B. Escrig-Tena, et al. (2009). "An empirical assessment of the EFQM

Excellence Model: Evaluation as a TQM framework relative to the MBNQA Model." Journal of Operations Management 27: 122.

10. Chang, J. Y., J. N. Choi, et al. (2008). "Turnover of highly educated R\&D professionals: The role of pre-entry cognitive style, work values and career orientation." \ournal of Occupational and Organizational Psychology 81: 299-317.

11. Clarke, T. E. (2002). "Unique Features of an R\&D Work Environment and Research Scientists and Engineers." Knowledge, Technology, \& Policy 15(3): 58-69.

12. Cohen, l., L. Manion, et al. (2000). Research Methods in Education. London, Routledge Falmer.

13. Daniels, K. and A. Bailey (1999). "Strategy development processes and participation in decision-making: predictors of role stressors and job satisfaction." Journal of applied management studies 8(1): 27-42.

14. Deming, W. E. (1986). Out of the Crisis. Cambridge, Massachusetts, London, The MIT Press.

15. EFQM (2010). EFQM Excellence Model. Brussels, Belgium, European Foundation for Quality Management.

16. Eskildsen, J. K. and J. J. Dahlgaard (2000). "A causal model for employee satisfaction." Total Quality Management 11(8): 1081-1094.

17. European-Union. (2012). "R \& D expenditure." Retrieved 07/10/2013, 2013, from

http://epp.eurostat.ec.europa.eu/statistic s_explained/index.php/R \%26_D_expendi ture.
18. Flynn, B. B., R. G. Schroeder, et al. (1994). "A framework for quality management research and an associated measurement instrument." \ournal of Operations Management 11(4): 339-366.

19. Goetsch, D. L. and S. M. Davis (1994). Introduction to Total Quality: Quality, Productivity, Competitiveness. New York, Macmillan College Publishing Company.

20. Guimaraes, T. (1996). "TQM's impact on employee attitudes." The TQM Magazine 8(1): 20 -25.

21. Hair, J. F., R. E. Anderson, et al. (1992). Multivariate Data Analysis. New York, Macmillan Publishing.

22. Ho, D., V. Duffy, et al. (1999). "Am Empirical Analysis of Effective TQM Implementation in the Hong Kong Electronics Manufacturing Industry." Human Factors and Ergonomics in Manufacturing 9(1): 1-25.

23. Igbaria, M. and T. Guimaraes (1993). "An examination of the antecedents of turnover

propensity of engineers: An integrated model." Lournal of Engineering and Technology

Management 9: 101-126.

24. Iqbaria, M. and S. R. Siegel (1992). "An Examination of the antecedents of turnover

propensity of engineers: An integrated model." Journal of Engineering and Technology

Management 9: 101-126.

25. Ishikawa, K. (1985). What is total quality control? The Japanese way. London, Prentice-Hall International, Inc.

26. IS09000 (2000). ISO 9000: Quality Management Systems - Fundamental and Vocabulary. Geneva, International Organization for Standardization. 
27. IS09001 (2008). Quality management systems - Requirements. Geneva, International

Organization for Standardization.

28. Jun, M., S. Cai, et al. (2006). "TQM practice in maquiladora: Antecedents of employee satisfaction and loyalty." Џournal of Operations Management 24: 791-812.

29. Kim, S. (2000). "The effect of participative strategic planning process on job satisfaction: the experience of local government agencies." Korean Journal of Policy Studies 15(2): 41-55.

30. Kochanski, J. and G. Ledford (2001). ""How To Keep Me"-Retaining Technical Professionals." Research-Technology Management 44(3): 31-38.

31. Kohlbacher, M. (2010). "The effects of process orientation: a literature review." Business

Process Management Journal 16(1): 135152.

32. Lam, S. S. K. (1995). "Quality management and job satisfaction: An empirical study." International Journal of Quality \& Reliability Management 12(4): 7.

33. Lazar, G. (2001). "Keep your key people." Electronic Business 27(86-94).

34. Maslow, A. (1943). "A theory of human motivation." Psychological Review 50: 370-396.

35. MBNQA (2010). Malcolm Baldrige National Quality Award. Gaithersburg, MD, USA, National Institute of Standards and Technology.

36. Meyer, J. P., D. J. Stanley, et al. (2002). "Affective, Continuance, and Normative Commitment to the Organization: A Metaanalysis of Antecedents, Correlates, and Consequences." \ournal of Vocational Behavior 61: 20-52.
37. Morrow, P. C. (1997). "The measurement of TQM principles and work-related outcomes." \ournal of Organizational Behavior 18: 363-376.

38. Nunnally, J. (1967). Psychometric Theory. New York, McGraw-Hill, Inc.

39. Oakland, J. S. (2003). Total Quality Management: Text With Cases. Oxford, Butterworth

Heinemann.

40. Ooi, K. B., N. A. Bakar, et al. (2007). "Does TQM influence employees' job satisfaction? An

empirical case analysis." International Lournal of Quality \& Reliability Management 24(1): 16.

41. Powell, T. C. (1995). "Total quality management as competitive advantage: a review and empirical study." Strategic Management Journal 16(1): 5-37.

42. Pugh, D. S., D. J. Hickson, et al. (1968). "Dimensions of Organization Structure." Administrative Science Quarterly 13(1): 65-105.

43. Salasin, J. and L. Hattery (1977). The Management of Federal Research and Development: An Analysis of Major Issues and Processes. Mclean, VA, The Mitre Corporation.

44. Samson, D. and M. Terziovski (1999). "The relationship between total quality management practices and operational performance." \ournal of Operations Management 17: 16.

45. Saraph, J. V., P. G. Benson, et al. (1989). "An Instrument for Measuring the Critical Factors of Quality Management." Decision Sciences 20: 810-829.

46. Spector, P. E. (1985). "Measurement of Human Service Staff Satisfaction: Development of the Job Satisfaction 
Survey." American Journal of Community Psychology 13(6): 693-713.

47. Teh, P.-L., C.-C. Yong, et al. (2009). "Does total quality management reduce employees' role conflict?" Industrial Management \& Data Systems 109(8): 1118-1136.

48. Tutuncu, O. and D. Kucukusta (2006). "Relationship Between Job Satisfaction and Business Excellence: Empirical Evidence from Hospital Nursing Departments." \ournal of Comparative International Management 9(2): 40 - 57.

49. Tutuncu, O. and D. Kucukusta (2007). "Relationship between Organizational Commitment and EFQM Business Excellence Model: A Study on Turkish Quality Award Winners." Total Quality Management 18(10): 1083-1096.

50. Ugboro, I. O. and K. Obeng (2000). "Top management leadership, employee empowerment, job satisfaction, and customer satisfaction in TQM organizations: an empirical study " Lournal of Quality Management 5(2): 247-272.

51. Voon, M. L., L. M. Chiun, et al. (2011). "The influence of leadership styles on employees' job satisfaction in public sector organizations in Malaysia." International Journal of Business, Management and Social Sciences 2(1): 2432.

52. Wetzels, M., K. d. Ruyter, et al. (2000). "Antecedents and consequences of role stress of retail sales persons." Journal of Retailing and Consumer Services 7: 65-75.

53. Yusof, S. R. M. and E. Aspinwall (2000). "Total quality management implementation frameworks: Comparison and review." Total Quality Management 11(3): 281294. 